\title{
MICROSTRIP ANTENNAS FOR MOBILE TELEPHONE HANDSET WITH REDUCED RADIATION HAZARDS
}

S. Mridula, ${ }^{1}$ Jacob George ${ }^{2}$ and P. Mohanan ${ }^{1}$

'Department of Electronics

Cochin University of Science and Technology

Cochin 682 022, Kerala, India

${ }^{2}$ Department of Electrical Engineering

Division of Telecommunication Technology and Electromagnetics

Eindhoven University of Technology

5600 M B Eindhoven, The Netherlands

Received 29 June 1999

ABSTRACT: $A$ novel antenna configuration comprised of two circular microstrip antennas (CMAs) resonating in the $T M_{11}$ and $T M_{21}$ modes, producing radiation characteristics suitable for a mobile telephone handset, is presented. The antennas operating at the same frequency are placed back to back with a separation comparable to the thickness of a typical handset. The radiation pattern consists of a region of reduced radiation intensity, which minimizes the radiation hazards to the user. (c) 1999 John Wiley \& Sons, Inc. Microwave Opt Technol Lett 23: 370-372, 1999.

Key words: microstrip antenna; radiation hazards; mobile communication

23, No. 6, December 201999 


\section{INTRODUCTION}

The field of wireless communications is growing at an explosive rate. The worldwide activities in this growth industry are an indication of its importance. Antenna designers have already made significant creative contributions to mobile communications systems, and optimizing the personal mobile antenna is now a priority task. The monopole antenna has been the dominant radiating element in mobile telephones by virtue of its omnidirectional radiation pattern, large bandwidth, and low cost [1]. But the need for a more compact, lightweight antenna makes the microstrip antenna an ideal substitute for mobile terminals. Also, the conventional antennas presently used in handsets cause radiation hazards to the user [2]. This necessitates the requirement for an antenna, which reduces the high specific absorption rate (SAR), in the user's head. Few configurations with reduced radiation toward the user's head have been proposed in the literature. But they either exhibit reduced radiation intensity in an entire hemisphere [3,4] or have a complex geometry [5]. Recently, Rajanish and Vedavathy [6] theoretically proposed the possibility of an antenna configuration comprised of two CMAs resonating in the $\mathrm{TM}_{11}$ and $\mathrm{TM}_{02}$ modes with reduced radiation hazards to the user. In this paper, we present the experimental demonstration of an alternative configuration incorporating two CMAs resonating in the $\mathrm{TM}_{11}$ and $\mathrm{TM}_{21}$ modes with more than $35 \%$ size reduction. This configuration exhibits minimum radiation in one quadrant, and fairly good coverage over the other three quadrants.

\section{DESIGN AND EXPERIMENTAL DETAILS}

The CMA resonating in the fundamental $\mathrm{TM}_{11}$ mode radiates a broad-side directed beam, whereas the higher order $\mathrm{TM}_{02}$ and $\mathrm{TM}_{21}$ modes radiate with a null in the broad-side direction [7]. Since the area of a $\mathrm{TM}_{21}$ mode CMA is nearly $35 \%$ less than that of a $\mathrm{TM}_{02}$ mode CMA, this mode is made use of in reducing the radiation toward the user's head.

The CMAs are both designed for a resonant frequency of $2 \mathrm{GHz}$, and are etched on a substrate of thickness $h=0.16$ $\mathrm{cm}$, with a relative permittivity of $\varepsilon_{r}=4.5$. The $\mathrm{TM}_{11}$ - and $\mathrm{TM}_{21}$-mode CMAs of radii $r_{1}=2.02 \mathrm{~cm}$ and $r_{2}=3.38 \mathrm{~cm}$, respectively, are fed at distances of $\rho_{1}=0.7 \mathrm{~cm}$ and $\rho_{2}=2$ $\mathrm{cm}$. Finite ground planes of radii 2.2 and $3.5 \mathrm{~cm}$, respectively, are used for the above antennas. They are placed back-to-back at a separation of $2.5 \mathrm{~cm}$ (typical thickness of commercially available handsets), with the $\mathrm{TM}_{21}$-mode antenna facing the user and the $\mathrm{TM}_{11}$-mode antenna away from the user, as shown in Figure 1. The antennas are mounted in such a way so as to match the polarization. They are excited in phase and amplitude using a $3 \mathrm{~dB}$ power divider. Figure 2 shows the return loss characteristics of individual antennas, along with that of the proposed configuration. From the figure, it is observed that the $\mathrm{TM}_{11}$ and $\mathrm{TM}_{21}$ CMAs operate in the same frequency band with a $2: 1$ VSWR impedance bandwidth of 2.1 and $1.5 \%$, respectively. The combined antenna configuration gives a bandwidth of $4.7 \%$.

The radiation patterns of the antenna along $\phi=0,45,90$, and $135^{\circ}$ planes are shown in Figure 3 . The figure indicates considerable reduction in the SAR in the quadrant facing the user [8]. This region forms a zone of silence where the user's head can be located. The suitability of the proposed antenna for mobile telephone handsets is thus confirmed. Proper spacing, excitation phase, or amplitude of the $\mathrm{TM}_{11^{-}}$and $\mathrm{TM}_{21}$-mode CMAs can trim the radiation pattern further. The combined antenna configuration exhibits a gain enhance-

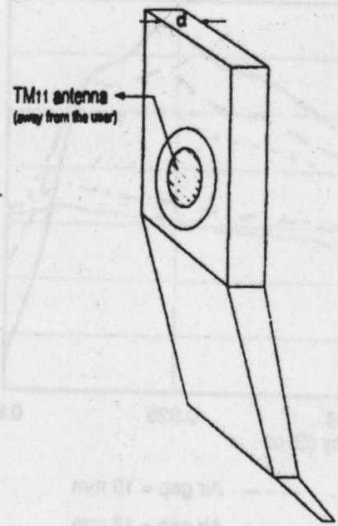

(a)

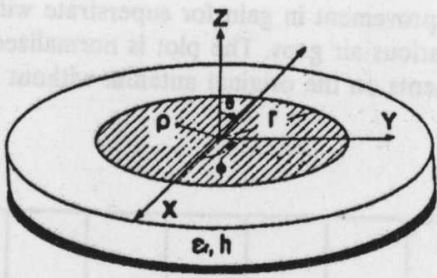

(c)

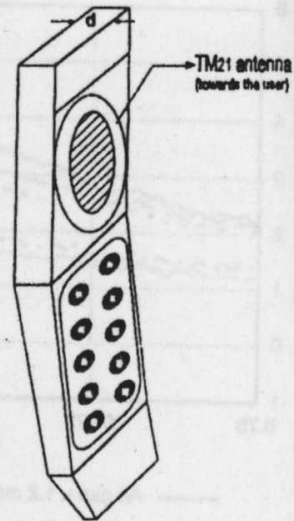

(b)
Figure 1 Proposed antenna configuration on a mobile handset. (a) Back view. (b) Front view. (c) Geometry of the microstrip antenna element

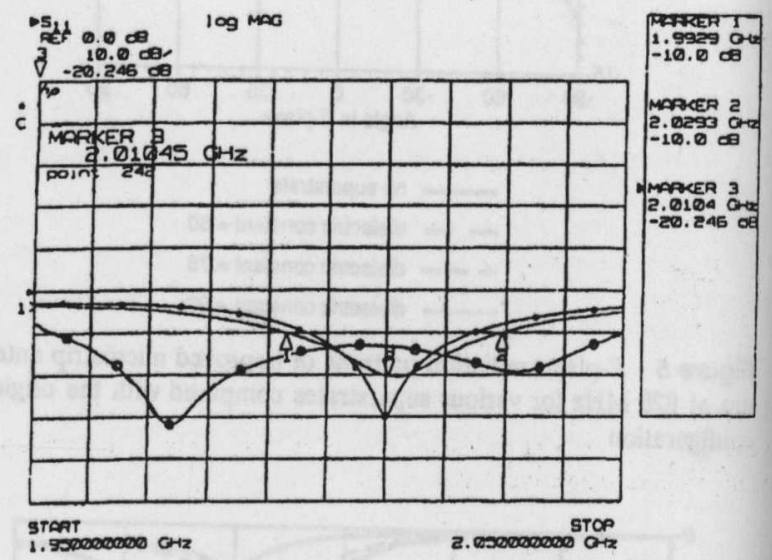

Figure 2 Variation of return loss with frequency for the two antennas along with that of the proposed configuration. - $\mathrm{TM}_{11}$ antenna alone, $\leftrightarrow \mathrm{TM}_{21}$ antenna alone, $\longrightarrow \mathrm{TM}_{11}$ and $\mathrm{TM}_{21}$ placed back-to-back and separated by $2.5 \mathrm{~cm}$

ment with respect to a standard CMA, as shown in Figure 4. This is due to the constructive interference between the back lobe and front lobe of the CMAs.

\section{CONCLUSIONS}

A compact microstrip antenna configuration suitable for mobile telephone handsets is developed. The radiation characteristics of this novel configuration show reduced radiation intensity in the region facing the user's head. 


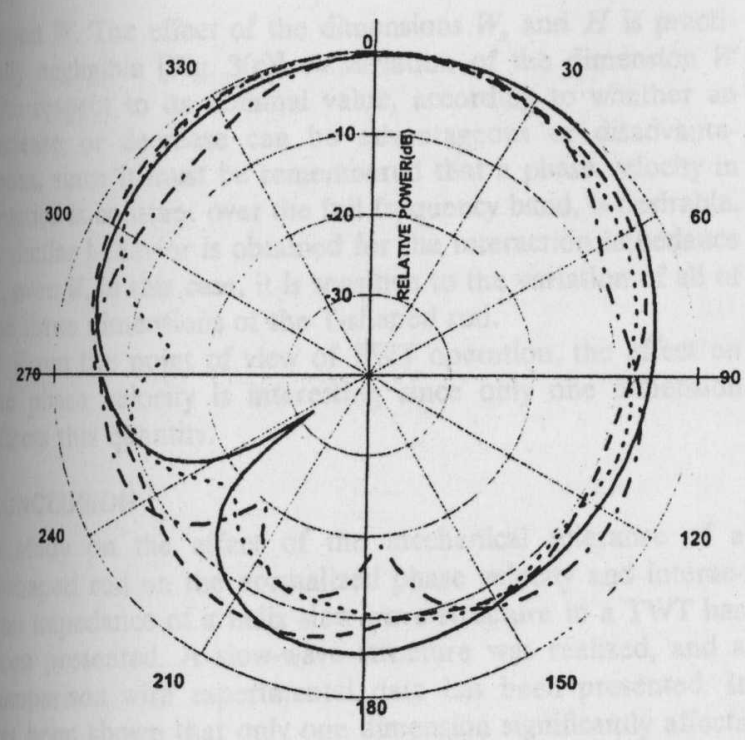

Figure 3 Radiation pattern of the antenna configuration in different planes. $-\phi=0^{\circ},---\phi=45^{\circ}, \cdots \cdots \phi=90^{\circ}, \cdots \cdots \cdot$. $\phi=135^{\circ}$

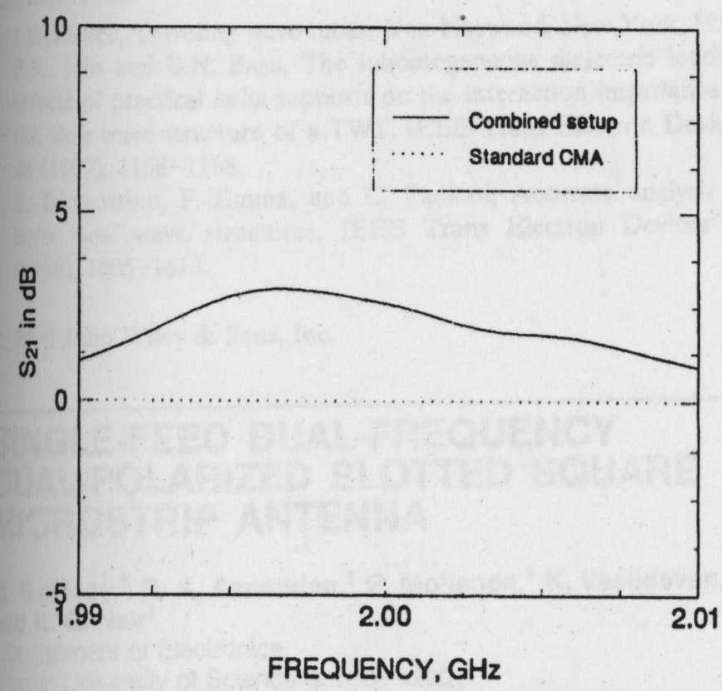

Figure $4 S_{21}$ of the proposed antenna configuration along the boresight with respect to that of a standard circular microstrip antenna operating in the $\mathrm{TM}_{11}$ mode

\section{REFERENCES}

1. A. Serrano-Vaello, and D. Sanchez-Hernandez, Printed antennas suitable for dual-band GSM/DCS 1800 mobile handsets, Electron Lett 34 (1988), 140-141.

2. Q. Balzano, O. Garay, and T.J. Manning, Electromagnetic energy exposure of simulated users of portable cellular telephones, IEEE Trans Veh Technol 44 (1995), 390-403.

3. R.B. Waterhouse, Printed antenna suitable for mobile communication handsets, Electron Lett 33 (1997), 1831-1832.

4. K. Takei, H. Okabe, and Y. Imakado, TEM slot antenna for personal handy-phone terminal, Electron Lett 33 (1997), 732-733.

5. H.O. Ruoss and F.M. Landstorfer, Slot antenna for hand held mobile telephones showing significantly reduced interaction with the human body, Electron Lett 32 (1996), 513-514.

6. Rajanish and T.S. Vedavathy, Novel microstrip antennas for mobile handset, Proc 6th Nat Symp Antennas Propagat (APSYM-98), Cochin, India, Dec. 1998, pp. 96-99. 
7. L. Shafai and A.A. Kishk, "Analysis of circular microstrip antennas," Handbook of microstrip antennas, J.R. James and P.S. Hall (Editors), Peter Peregrinus, London, England, 1989, vol. 1, pp. 45-110.

8. R.Y. Tay, Q. Balzano, and N. Kuster, Dipole configurations with strongly improved radiation efficiency for hand-held transceivers, IEEE Trans Antennas Propagat 46 (1998), 798-806.

(c) 1999 John Wiley \& Sons, Inc.

CCC 0895-2477/99 